\title{
A Ricardian analysis of the impact of climate change
}

\author{
on agriculture in Germany ${ }^{1}$
}

\author{
Christian Lippert, Tatjana Krimly, Joachim Aurbacher ${ }^{2}$
}

\begin{abstract}
Based on a Ricardian analysis accounting for spatial autocorrelation and relying on recent climate change forecasts at a low spatial scale, this study assesses the impact of climate change on German agriculture. Given the limited availability of data (e.g., the unknown average soil quality at the district level), a spatial error model is used in order to obtain unbiased marginal effects. The Ricardian analysis is performed using data from the 1999 agricultural census along with data from the network of German weather observation stations. The cross-sectional analysis yields an increase of land rent along with both a rising mean temperature and a declining spring precipitation, except for in the Eastern part of the country. The subsequent simulation of local land rent changes under three different IPCC scenarios is done by entering into the estimated regression equations spatially processed data averages for the period between 2011 and 2040 from the regional climate model REMO. The resulting expected benefits arising from climate change are represented in maps containing the 439 German districts; the calculated overall rent increase corresponds to approximately $5-6 \%$ of net German agricultural income. However, in the long run, when temperature and precipitation changes will be more severe than those simulated for 2011-2040, income losses for German agriculture cannot be excluded.
\end{abstract}

\section{Introduction: climate change in Germany}

As a consequence of the greenhouse effect, an on-going change of the global climate is projected for the next decades. The IPCC report (2007a) expects an increase of the mean global temperature by $1.8^{\circ} \mathrm{C}$ to $4.0^{\circ} \mathrm{C}$. Furthermore, precipitation and the occurrence of extreme weather events will increase. Over the past 100 years the average temperature increase in Europe was $1^{\circ} \mathrm{C}$, compared to a global average temperature increase of about $0.7^{\circ} \mathrm{C}$ (IPCC 2007a). The mean temperature in Europe is expected to increase by $2.1^{\circ} \mathrm{C}$ to $5.3^{\circ} \mathrm{C}$ by the end of this century; again, Europe shows a stronger warming trend than the global average. Since agriculture is an economic activity which strongly depends on the climate setting and is particularly responsive to climate changes, it is important to understand how such changes may affect agricultural productivity and profitability.

\footnotetext{
${ }^{1}$ This paper is an author-created version of a publication in Climatic Change. The original publication is available at www.springerlink.com: C. Lippert, T. Krimly, J. Aurbacher, Climatic Change, 2009, DOI 10.1007/s10584-009-9652-9 (published online: 18 August 2009).

${ }^{2}$ Institute for Farm Management (410a), Section of Production Theory and Resource Economics, Universität Hohenheim, Schloss Osthof-Süd, 70593 Stuttgart, Germany e-mail: clippert@uni-hohenheim.de.
} 
In principle, there are two main approaches to assessing the impact of climate change (Mendelsohn 2007): one way is to run simulation models, the parameters of which have to be obtained from controlled experiments; the other way is to conduct a cross-sectional analysis observing the (economic) system across different locations in order to determine how the system may adapt to different climates. This method, usually referred to as a Ricardian approach, corresponds to the Hedonic Pricing of environmental attributes. Using observed land prices, its basic purpose is " [...] to infer the willingness to pay in agriculture to avoid a $3^{\circ} \mathrm{C}$ temperature rise (for example) by examining two agricultural areas that are the same in all respects except that one has a climate on average $3^{\circ} \mathrm{C}$ warmer than the other" (Kolstad 2000: 317; for a broader description of the underlying theory cf. Mendelsohn et al. 1994; Mendelsohn and Reinsborough 2007: 10f.; Lang 2007: 425f.). In the case of competitive markets, assuming that land prices at different locations have reached their long-run equilibrium, this approach accounts for both the direct effects of climate on crop yields and the indirect effects resulting from the substitution or adaptation of farming activities.

Whereas the Ricardian approach has been frequently used for Northern America (e.g., Mendelsohn et al. 1994; Polsky and Easterling 2001; Schlenker et al. (2005; 2006); Deschênes and Greenstone 2007; Mendelsohn and Reinsborough 2007), until now only one study has focused on Central Europe. Lang (2007) analysed weather data along with 1990 through 1994 panel data from farmers in former West Germany, and found, among other results, an inversely u-shaped relationship between the local temperature sum during the growing season and land rental prices. He predicted that "[...] German farmers will be winners of climatic change in the short run, with maximum gains occurring at a temperature increase of $+0.6^{\circ} \mathrm{C}$ against current levels" (Lang 2007: 423).

When compared with the mentioned experimental-simulation approach, one advantage of a Ricardian analysis is that it is based on real-world adaptation measures which have been brought about by a trial-and-error process involving many farmers well acquainted with their specific local production conditions. A major weakness of the Ricardian approach consists in the inadequacy of extrapolating it for climatic settings (e.g., temperature, $\mathrm{CO}_{2}$-fertilisation) which have not been observed so far (i.e., settings which are not covered by the data set used to estimate the Hedonic Pricing function). Furthermore, the approach "must work hard not to be biased by omitted variables that are correlated with climate" (Mendelsohn 2007: 2).

One promising way to cope with the problem of spatial autocorrelation is to explicitly consider spatial autocorrelation of the residuals when estimating the parameters of the Hedonic Pricing model. Up to now, this has rarely been done in the context of climate change impact assessment. Exceptions are Schlenker et al. (2006: 116), Deschênes and Greenstone (2007: 366), who adjusted the standard errors of their estimated models for spatial dependence, and to a certain extent Polsky and Easterling (2001), who included additional explanatory variables referring to a larger spatial scale (districts) in their county-based analysis.

Our approach takes only long-term climatic variables into consideration although Schlenker and Roberts (2006) indicate that already single day events can have significant influence on yields. However, daily weather data for Germany was not available to us. Deschênes and Greenstone (2007) criticized the Ricardian approach which in their analysis turned out to be strongly influenced among other things by the choice of variables included into the estimated equation. Alternatively, they suggested and applied an approach where they used the observed year-to-year variation of precipitation and temperature to explain agricultural profits in the United States. However, as they admit, in doing so farmers' damages due to climatic change are systematically overstated because the statistical model then does not account for complete adaptation which is impossible when only reacting to the weather events of single years. 
The objective of this paper is to assess the impact of climate change on German agriculture using recent climate change forecasts at a low spatial scale, relying on a Ricardian analysis which accounts for spatial autocorrelation. In the next section we will present an appropriate statistical model relying on a spatial weight matrix (Section 2.1) as well as the data (Section 2.2) that will finally be used to estimate two Hedonic Pricing functions (Section 2.3). Then, by means of these functions, the economic impact of three different climate change scenarios (Section 3.1) on the profitability of German Agriculture will be presented (Section 3.2) and discussed (Section 4).

\section{Empirical analysis}

\subsection{Statistical model}

In the following, a functional relationship between the rental price $r_{i}$ for farmland at location $i$ and different exogenous factors $x_{c}$ and $x_{n c}$ is assumed:

$$
r_{i}=f\left(x_{c}, x_{n c}\right),
$$

where $x_{c}$ is a vector of climate characteristics such as mean annual temperature or average precipitation in different months, and $x_{n c}$ stands for a vector of non-climate variables such as grassland share of overall agricultural land or soil quality. Since it is impossible to obtain sufficient data for all relevant variables $x_{n c}$ when estimating the Hedonic Pricing function (1), we explicitly considered spatial autocorrelation. Equations 2 and 3 outline the general version of a corresponding spatially autoregressive model (Anselin 1988: 34ff.; LeSage 1999: 52f.) which accounts for both spatial lag dependence and spatial error dependence (cf. Patton and McErlean 2003: 37):

$$
\begin{aligned}
r & =\rho W_{1} r+X \beta+u \\
u & =\lambda W_{2} u+\varepsilon \\
\text { with } \quad \varepsilon & \sim N\left(0, \sigma^{2} I\right),
\end{aligned}
$$

where

$r=n \times 1$ vector containing the reported average farmland rental prices, each associated with a specific administrative district $i(i=1, \ldots, n)$;

$X=n \times(1+k)$ design matrix containing a set of observations for $k$ explanatory climate and non-climate variables;

$W_{s}=$ given $n \times n$ spatial weight matrices $\left(\mathrm{s}=1,2 ; W_{1}\right.$ and $W_{2}$ may be identical);

$I=n \times n$ identity matrix;

$u=n \times 1$ vector of the spatially correlated residuals;

$\varepsilon=n \times 1$ vector of normally distributed errors $\left(\right.$ mean $=0$, variance $\left.=\sigma^{2}\right)$.

The parameters to be estimated are

$\rho=$ spatial lag coefficient;

$\beta=(1+k) \times 1$ vector containing the regression coefficients for the explanatory variables;

$\lambda=$ coefficient reflecting the spatial autocorrelation of the residuals $u_{i}$. 
For the following estimations, we will always use a standardised first-order contiguity matrix $\left(W=W_{1}=W_{2}\right)$. Notice that such a matrix reflects simple neighbourhood alone (in our case between the $n=439$ districts of Germany): in every row $i$ a 0 is assigned to every district $j \neq i$ that does not adjoin with district $i$; the same is done for all diagonal elements of the $n \times n$ matrix. When two districts $i$ and $j$ are contiguous, $l / g_{i}$ will be assigned to the intersection of the $i^{\text {th }}$ row and the $j^{\text {th }}$ column (where $g_{i}$ is the number of districts which have a common border with district $i$ ). With $W$ set up like this, the $n \times 1$ vector $W r$ gives for every district $i$ the mean rental price observed in its contiguous districts. A significant positive parameter $\rho$ would hint at a self-enforcing effect of higher farmland rental prices (a case of spatial dependency of rental prices). Solving Eq. 3 for the vector of the spatially correlated residuals (u) and entering the resulting term into Eq. 2 gives:

$$
\begin{aligned}
r & =\rho W r+X \beta+(I-\lambda W)^{-1} \varepsilon \\
<=(I-\lambda W) r & =(I-\lambda W) \rho W r+(I-\lambda W) X \beta+\varepsilon \\
<\quad r & =\rho W r+\lambda W(r-\rho W r+X \beta-\lambda W X \beta+\varepsilon .
\end{aligned}
$$

A problem occurs when one or more of the often spatially correlated factors which influence rental prices are not accounted for in the statistical model, as can be easily demonstrated by looking at Eq. 4a: neglecting possible spatial dependency (i.e., assuming $\rho \approx 0$ ), Eq. $4 \mathrm{a}$ is reduced to

$$
\begin{aligned}
\varepsilon & =r-X \beta-\lambda W r+\lambda W X \beta \\
\Leftrightarrow \quad & \varepsilon=u-\lambda W r+\lambda W X \beta .
\end{aligned}
$$

If all relevant explanatory variables were contained in $X$, the values $r_{i}$ would increase and decrease in line with $X_{i} \beta$ (apart from the "white noise" $\varepsilon$; i.e., $\varepsilon=u$ ). The parameter $\lambda$ then would be close to zero. On the other hand, if important spatially correlated explanatory variables were not contained in $X \beta$, the residuals $u_{i}$ would have to be corrected by $\lambda W r$ in order to obtain a vector of normally distributed residuals $\varepsilon$. (Note that in the latter case, $\lambda W X \beta$ will contain only normally distributed elements, whereas $\lambda W r$ will positively depend on $u$.) A significant value for $\lambda$ means that there is at least one spatially correlated feature which is not reflected by the exogenous variables used in the model, but which affects the observed rental price.

Subsequent regression analyses always yielded a highly significant Moran's I as well as a highly significant value for $\lambda$ (which indicates that some of the relevant explanatory variables $x_{c}$ and $x_{n c}$ were not included in $X$ ), whereas a significant parameter $\rho$ could not be found. Consequently, our parameter estimates presented in the following are based on the simple spatial error model:

$$
r=X \beta+(I-\lambda W)^{-1} \varepsilon .
$$

The Eq. 4b were estimated using MATLAB along with the "Econometrics Toolbox" by LeSage (2003) (for the spatial error model and the iterative maximum likelihood estimation employed, cf. LeSage 1999: 48f.).

\subsection{Data}

Sources for land data Data regarding the districts' utilisable agricultural area (UAA) and the grassland share of that area were taken from the 1999 agricultural census (Statistische Ämter des Bundes und der Länder 2001). All together, the UAA of the 439 German districts 
amounted to a total of 17,157,906 hectares. The 1999 yearly rental price $r$ for farmland (in Euro per hectare UAA) by district (Landkreis) was kindly communicated by Statistisches Landesamt Baden-Württemberg (2007). For 14 of the 439 German districts, part of the agricultural census data was lacking and had to be replaced by careful assumptions based on observations from similar districts (using a spatial weight matrix $W$, it was impossible to omit the corresponding districts from the analysis). Relying on rental prices instead of farmland prices has the advantage that we need not consider some factors which strongly distort farmland prices, especially in the densely populated regions of Central Europe. For example, the high prices for farmland which may become building land in the medium term have nothing to do with real agricultural productivity. Renting farmland is quite common in Germany: in 1999, 68.4\% of German farms rented at least part of their land; the share of rented land was about $50 \%$ of overall cultivated farmland in West Germany and about $90 \%$ in East Germany (BMVEL 2001: 12). Since land rent contracts always expire after some years the reported land rental prices to be paid on a yearly basis by the tenant (who is not entitled to sell the land and who will not benefit from a land sale by the owner) do not contain the option value of the corresponding plots of land for a possible urban development. They are just reflecting the agricultural productivity of the land. In contrast, purchase prices for farmland also include the mentioned option value.

Sources for climate data This analysis used data from weather observation stations from the German Weather Service (DWD 2007). This dataset contains the latitude and longitude of the station (in geographic coordinates), altitude, and averages of temperature, precipitation and sunshine duration over 30 years (1961-1990) for the whole year and for each month. The precipitation dataset consists of 4748 stations, while the dataset for temperatures includes 675 stations. For the future scenarios, climate data from the REMO model (MPI on behalf of the Umweltbundesamt 2006) was used (cf. Section 3.1). These data were available via the World Data Center for Climate and consist of spatially explicit climate data with a resolution of $10 \mathrm{~km} * 10 \mathrm{~km}$ in a binary file type (ieg). Furthermore, a shapefile of the German districts was available.

Processing of the climate data First, as all geographic data were assumed to conform to the WGS 1984 system, they were projected into the UTM zone $32 \mathrm{~N}$ coordinate system to obtain a length-preserving map. In the second step, all observations of weather stations with an altitude higher than $1000 \mathrm{~m}$ were taken out of the sample, because it was assumed that these stations are on mountains that are significantly above the agricultural area of the region and do not reflect conditions for agriculture. This left 4710 stations for precipitation and 663 stations for temperature. The observations of these stations have been interpolated spatially. For this purpose, the method of inverse distance weighting was used with a variable search radius to include 12 points. The power of the distance function was set to two and the output raster had a cell size of $1000 \mathrm{~m}$. A validation of the method by leaving out randomly selected $5 \%$ of the $m$ observations and comparing the estimated values for historic annual average temperature and spring precipitation to the measured values gave an average deviation of $-0.25^{\circ} \mathrm{C}$ with a standard deviation of $0.699^{\circ} \mathrm{C}$ for temperature $(0.05 \mathrm{~m} \approx 33)$ and an average deviation of 3.0 $\mathrm{mm}$ with a standard deviation of $22 \mathrm{~mm}$ for spring precipitation $(0.05 \mathrm{~m} \approx 236)$. Other interpolation methods like spline and kriging were tested and usually resulted in worse results, so the method of inverse distance weighting was chosen. The resulting grid was used to obtain zonal statistics taking the shapes of the districts into account. The corresponding values were aggregated as arithmetic means. This resulted in average values for each district for mean annual temperatures, yearly sunshine duration and seasonal precipitation sums calculated from the observations obtained between 1961 and 1990 . 


\subsection{Parameter estimates}

Along with some further variables $x_{n c}$, a multitude of climate variables $x_{c}$ were tested to explain the 1999 land rental prices, which were assumed to be equilibrium prices resulting from the climate settings prevailing in 1961 through 1990. The tested climate factors $x_{c}$ comprised linear and quadratic variables for mean annual temperature, annual precipitation and precipitation in different months or seasons. Also, yearly sunshine duration and dummy variables for dry and humid areas were included in the analysis. Among the factors $x_{n c}$, the district's grassland share, its altitude and a dummy variable for East Germany (the former GDR) were considered. Variables usually correlated with prices for building land, such as the district's population density, were omitted, since their influence on agricultural land rental prices is low when compared to purchase prices of farmland. These latter prices are also affected by expectations regarding the land's possible future transformation into very valuable building land.

Livestock density, which affects land rental prices in some German regions, was not included in the estimated Hedonic Pricing equations. The reason is that adapting animal husbandry may be one important means farmers will use to cope with climate change. Consequently, livestock density should not be expected to remain constant over time. When altitude and mean annual temperature were used as explanatory variables in separate models both variables were highly significant. However, when they are simultaneously included in one regression model, altitude is no longer significant. (The correlation coefficient of altitude and mean annual temperature is $-0.68^{* * *}$.) Hence, altitude was removed from the final equations, since it is temperature and not altitude that will change in the future.

The marginal effects for the two final models are given in Table 1. An inversely u-shaped relationship between temperature and land rental price, as in the study by Lang 2007, could not be found. However, it should be noted that Lang used temperature sums instead of mean temperature, studied another time period, and used a completely different sample covering only West Germany. In all, the high coefficients $\lambda$ indicate that important factors influencing land rent were not among the variables included in our matrices $X$. Unfortunately, there was no appropriate indicator for soil quality, which in reality strongly influences land rents and of course shows spatial autocorrelation.

The differences between the two models can be explained as follows: the grassland share significantly correlates with both spring precipitation (correlation coefficient $=0.61^{* * *}$ ) and mean annual temperature (correlation coefficient $=-0.34 * * *$ ); the grassland share itself correlates negatively with the rental price. Consequently, as long as farmers are allowed to relocate land from grassland use to crop farming, a spring precipitation decline and a temperature increase both tend to reduce the grassland share, resulting in, in addition to the marginal effects of model I, higher land rents. Thus, the marginal effects of precipitation and temperature are greater in model II, which implicitly allows for adaptation of the grassland share. Which of the two models is more appropriate depends on whether the future grassland share can be influenced by the farmers: at present, due to the cross-compliance restrictions linked to the direct payments of the Common Agricultural Policy (CAP), farmers are not allowed to transform large grassland areas to arable land. However, against the background of increasing world food prices, this constraint might be removed in ten or twenty years. Nevertheless, one has to keep in mind that other natural factors, especially the land's slope, can hamper the use of heavy machinery, and therefore, the shift to arable production. 
Table 1: Ricardian regression estimates explaining German land rental prices

\begin{tabular}{|c|c|c|c|}
\hline \multirow[b]{2}{*}{ Variable } & \multirow{2}{*}{$\begin{array}{l}\text { Mean of } \\
\text { the sample }\end{array}$} & \multicolumn{2}{|c|}{ Regression coefficients (t-statistics) $^{\mathrm{d}}$} \\
\hline & & Model I & Model II \\
\hline Constant (Euro/ha UAA) & $182.90^{\mathrm{c}}$ & $120.065(2.14)$ & $74.588(0.32)$ \\
\hline Grassland share in $\%$ of $\mathrm{UAA}^{\mathrm{a}}$ & 31.43 & $-1.735(-10.24)$ & - \\
\hline East Germany $($ yes $=1 ;$ no $=0)$ & 0.26 & $-192.154(-3.35)$ & $-218.780(-3.39)$ \\
\hline Spring precipitation (March-June) in $\mathrm{mm}^{\mathrm{b}}$ & 270.17 & - & $-0.397(-4.14)$ \\
\hline East Germany and Spring precipit. in $\mathrm{mm}^{\mathrm{b}}$ & 55.81 & $0.465(1.95)$ & $0.531(2.01)$ \\
\hline Mean annual temperature in ${ }^{\circ} \mathrm{C}^{\mathrm{b}}$ & 8.40 & $16.532(2.71)$ & $27.736(4.08)$ \\
\hline & $\lambda$ & $0.834(31.64)$ & $0.838(31.95)$ \\
\hline & corr. $R^{2}$ & $80.87 \%$ & $77.23 \%$ \\
\hline
\end{tabular}

Yearly land rent to be paid in 1999 on district average in Euro per hectare utilisable agricultural area (UAA), according to Statistisches Landesamt Baden-Württemberg (2007). Source: our own estimations based on data by Statistisches Landesamt Baden-Württemberg (2007), Statistische Ämter des Bundes und der Länder (2001), DWD (2007)

\footnotetext{
${ }^{a}$ Data from agricultural census 1999 (Statistische Ämter des Bundes und der Länder 2001)

${ }^{\mathrm{b}}$ Our own calculations (cf. Section 2.2) based on data by DWD (2007)

${ }^{\mathrm{c}}$ Mean district average in 1999

${ }^{\mathrm{d}}$ Both models estimated according to Eq. $4 \mathrm{~b}$ in Section 2.1, $\mathrm{n}=439$; in parentheses: asymptotic t-statistics; except for the constant of model II, all coefficients are statistically significant to at least $5 \%$.
}

\section{Estimated impact of different climate change scenarios on land rents}

\subsection{Scenarios}

The annual mean temperature in Germany increased by $0.8^{\circ} \mathrm{C}$ to $1.0^{\circ} \mathrm{C}$ in the $1990 \mathrm{~s}$, with an exceptionally strong temperature rise in southern and south-west Germany (Zebisch et al. 2005). Furthermore, a trend toward a stronger temperature increase in winter than in summer has been observed over the last 20 years. Precipitation shows strong seasonal and regional variation without any significant trends (Zebisch et al. 2005). However, winter precipitation definitely increased in the last 30 years, while summer precipitation showed only a slight change. Future mean temperature is expected to rise by $0.10^{\circ} \mathrm{C}$ to $0.45^{\circ} \mathrm{C}$ per decade, and precipitation is expected to increase in the wintertime and decrease in the summertime, both with strong regional variation (UBA 2006, Zebisch et al. 2005, IPCC 2007a, Gerstengarbe et al. 2005).

IPCC (2007b) scenario data underlying this study was taken from the regional climate model REMO, which is used for weather forecasting and climate simulations (Jacob 2001, UBA 2006). REMO is based on a former weather prediction model of the German Weather Service (Europamodell) and was further improved by the implementation of physical parameterisations of the global climate model ECHAM3/T42 and ECHAM4/T106 (Jacob and Podzun 1997, Jacob 2001).

$I P C C$ storyline $A 1 B$ describes a future world with very rapid economic growth and a global population that increases until the middle of this century and declines thereafter. This storyline is characterised by a balanced use of fossil and non-fossil energy resources. The $A 2$ storyline depicts a very heterogeneous future world with a continuously increasing population and a primarily regionally oriented economic development. Per capita economic growth and technological change are slower than in other scenario families. Storyline B1 describes a convergent future world with the same global population growth as in A1B. However, this storyline is characterised by a rapid change in economic structures towards a service and information economy, with a reduction in material intensity and the introduction of lowemission, resource-efficient technologies. 
To model these future scenarios, data from the REMO model (MPI on behalf of the Umweltbundesamt 2006) were used. From the REMO database, the results containing monthly means $(\mathrm{MM})$ for the three IPCC scenarios for the $21^{\text {st }}$ century, A1B, A2 and B1, were selected. Furthermore, the constant data fields longitude, latitude and altitude were included. REMO is spatially explicit on a raster of about $10 \mathrm{~km}$, and its 13189 data points cover an area that exceeds Germany. Among the available climate data, near surface air temperature (TEMP2), convective precipitation $(A P R C)$ and large scale precipitation (also referred to as stratiform precipitation) (APRL) were used. The years 2011 to 2040 were chosen as the scenario period. The data were manipulated using the software Climate Data Operators (CDO) (Schulzweida et al. 2007), while the spatial resolution was maintained. The average monthly precipitation was calculated as a sum of large scale precipitation and convective precipitation. The resulting sums of the months March to June have been added. As the initial figures were in units of $\mathrm{mm} / \mathrm{h}$, the result was multiplied by $732(30.5 * 24)$ to obtain data in units of $\mathrm{mm} / 4$ months. From these values, the means of the years 2011 to 2040 were calculated. The average temperature for this time period was calculated from the $2 \mathrm{~m}$ temperature (TEMP2) and converted from Kelvin to Centigrade. Next, the spatial data was projected into the UTM zone $32 \mathrm{~N}$ coordinate system using ESRI ArcGIS. Again, all observations with an altitude higher than $1000 \mathrm{~m}$ were removed from the sample. With the remaining 12119 data points, interpolation and statistics were carried out in the same way as described for the historic climate data in Section 2.2.

\subsection{Estimated land rent changes}

Spring precipitation and mean annual temperature in all IPCC scenarios were compared to the reference situation (Table 2). For both variables, the greatest increase can be found in storyline A2 with a rise in mean annual temperature by $1.57^{\circ} \mathrm{C}$ and an average increase in spring precipitation by $55.37 \mathrm{~mm}$. The smallest changes take place in scenario B1.

The distribution of the mean temperatures on the district level in the reference situation (1961-1990) shows mainly medium average temperatures in the upper half of Northwest and East Germany, with a slight increase when the distance from the sea is increased (Fig. 1a). The warmest regions can be found in the southwestern part of the Northwest, the southeastern part of the Central-West and the northwestern part of Baden-Wuerttemberg. The lowest mean temperatures prevail in the low mountain ranges of central and south Germany, e.g., the black forest in the southwest of Baden-Wuerttemberg, as well as in the Alps and their forelands in the south of Bavaria. As already mentioned, temperature is highly correlated with altitude. All scenarios show a clear temperature rise by more than $1.5^{\circ} \mathrm{C}$ in the main parts of BadenWuerttemberg and Bavaria and in the centre of Germany (Fig. 1b-d). The lowest warming is simulated for the southwestern part and the centre of the Northwest, and in the Ore Mountains in the south of East Germany.

Average spring precipitation in the reference scenario shows a clear increase from the east to the west (Fig. 2a). The lowest amounts, less than $200 \mathrm{~mm}$, can be found in East Germany and the highest in the southern part of Baden-Wuerttemberg, in Bavaria and in the south of the Northwest. All IPCC scenarios show, in the main parts of the Northwest and the East, an increase of the average spring precipitation. A strong increase of more than $100 \mathrm{~mm}$ is predicted for certain regions in the southwest of the Northwest, in the Alps (in the south of Bavaria) and the west of Baden-Wuerttemberg (Upper Rhine Valley) (Fig. 2b-d). In contrast, spring precipitation in the Black Forest region to the east of the Upper Rhine Valley decreases by more than $50 \mathrm{~mm}$. A decrease in spring precipitation can also be found in many districts of Bavaria and the Central-West, especially in scenarios A1B and B1. 
Table 2: Forecasted climate change and resulting estimated additional land rent

\begin{tabular}{|c|c|c|c|c|}
\hline $\begin{array}{l}\text { Scenario }^{\mathrm{a}} \\
\text { Time horizon }\end{array}$ & $\begin{array}{c}\text { Reference } \\
1961 \text {-' } 90^{-}\end{array}$ & $\begin{array}{c}\mathrm{A} 1 \mathrm{~B} \\
2011-{ }^{`} 40 \\
\end{array}$ & $\begin{array}{c}\mathrm{A} 2 \\
2011-{ }^{\prime} 40 \\
\end{array}$ & $\begin{array}{c}\mathrm{B} 1 \\
2011-{ }^{-} 40 \\
\end{array}$ \\
\hline Spring precipitation (March-June) in $\mathrm{mm}^{\mathrm{b}}$ & 270.17 & 314.18 & 325.54 & 302.02 \\
\hline East Germany and Spring precipitation in $\mathrm{mm}^{\mathrm{b}}$ & 55.81 & 70.83 & 71.36 & 67.41 \\
\hline Mean annual temperature in ${ }^{\circ} \mathrm{C}^{b}$ & 8.40 & 9.86 & 9.97 & 9.82 \\
\hline $\begin{aligned} \text { Model I: } & \text { total land rent increase }(\text { million } €)^{\mathrm{c}} \\
& \text { weighted average rent increase }(€ / \text { ha UAA) }\end{aligned}$ & & $\begin{array}{r}568.59 \\
33.14\end{array}$ & $\begin{array}{r}599.17 \\
34.92\end{array}$ & $\begin{array}{r}527.21 \\
30.73\end{array}$ \\
\hline $\begin{array}{l}\text { Model II: total land rent increase }(\text { million } €)^{\mathrm{c}} \\
\text { weighted average rent increase }(€ / \text { ha UAA) }\end{array}$ & & $\begin{array}{r}611.90 \\
35.66\end{array}$ & $\begin{array}{r}597.81 \\
34.84\end{array}$ & $\begin{array}{r}623.14 \\
36.32\end{array}$ \\
\hline
\end{tabular}

Source: our own estimations based on data by Statistisches Landesamt Baden-Württemberg (2007), Statistische Ämter des Bundes und der Länder (2001), DWD (2007) and MPI on behalf of the Umweltbundesamt (2006).

${ }^{a}$ Cf. the scenarios outlined in Section 3.1; reference situation for 1961-1990

${ }^{\mathrm{b}}$ Our own calculations based on REMO data and the methods described in Section 2; the mean of the predicted district averages for 2011 through 2040

${ }^{\mathrm{c}}$ Total estimated rent increase for Germany $=\sum_{\mathrm{i}} \mathrm{UAA}_{\mathrm{i}} *$ (Difference between the estimated land rent after climate change and the estimated land rent in 1999) ${ }_{i}$ for the 439 German districts $(i=1, \ldots, 439)$; for models I and II cf. Table 1

${ }^{\mathrm{d}}$ The utilisable agricultural areas $\left(\mathrm{UAA}_{\mathrm{i}}\right)$ of the districts were used as weights

Total land rent increases in all scenarios (Table 2). Using Model I, the highest increase in total land rent, 599 million $€$, is achieved in A2. Because spring precipitation only matters in East Germany, agriculture mainly profits from the temperature increase, which is highest in A2. The spatial distribution of the land rent changes is shown in Fig. 3b-d. Note that land rent changes shown in Figs. 3 and 4 are the difference between estimated land rents after the simulated climate change and the estimated reference land rent in 1999. The increases in land rent rise from north to south in West Germany. This is because the temperature increase in Baden-Wuerttemberg and Bavaria is greater than that in the Northwest. The greater increase in East Germany is caused by the rise in spring precipitation which there, in contrast to the West, has a positive impact on land rents because of the presently bad climatic water balance.

Model II shows a different picture: the increase of total land rent in A2 is lower than in the other scenarios (Table 2). This can be explained by the greater increase in spring precipitation, which is highly correlated to the grassland share. As a result, conditions for arable production get worse compared to A1B and B1. For East Germany, the land rent changes are similar to the development calculated with model I, but differ in the other parts of Germany (Fig. 4b-d). In regions where spring precipitation rises by more than $100 \mathrm{~mm}$ (Fig. 2b-d), including the southwest of the Northwest and the Upper Rhine Valley, conditions for arable production get less favourable and land rents decrease correspondingly. In contrast, as a consequence of a decline in spring precipitation and a rise in temperature, land rents clearly increase in some districts of Baden-Wuerttemberg and Bavaria which have high precipitation in the reference situation. In these regions, especially the Black Forest region (BadenWuerttemberg), conditions for agricultural production are improved. All together, scenario $\mathrm{B} 1$, which has the lowest increase in average spring precipitation, leads to a greater increase in total land rent than the other scenarios.

For the years 1998 through 2000, the average net national product (NNP) of German agriculture amounted to 10566 million Euros (BMVEL 2004: 127); thus the estimated overall rent increases caused by the predicted climate change correspond to between 5 and $6 \%$ of net agricultural income available to reward land, labour and capital used in German agriculture. The weighted average rent increases in the range of 31 to 36 Euros per hectare UAA (Table 2), which corresponds to 17 to $20 \%$ of the average rent in the reference situation. 


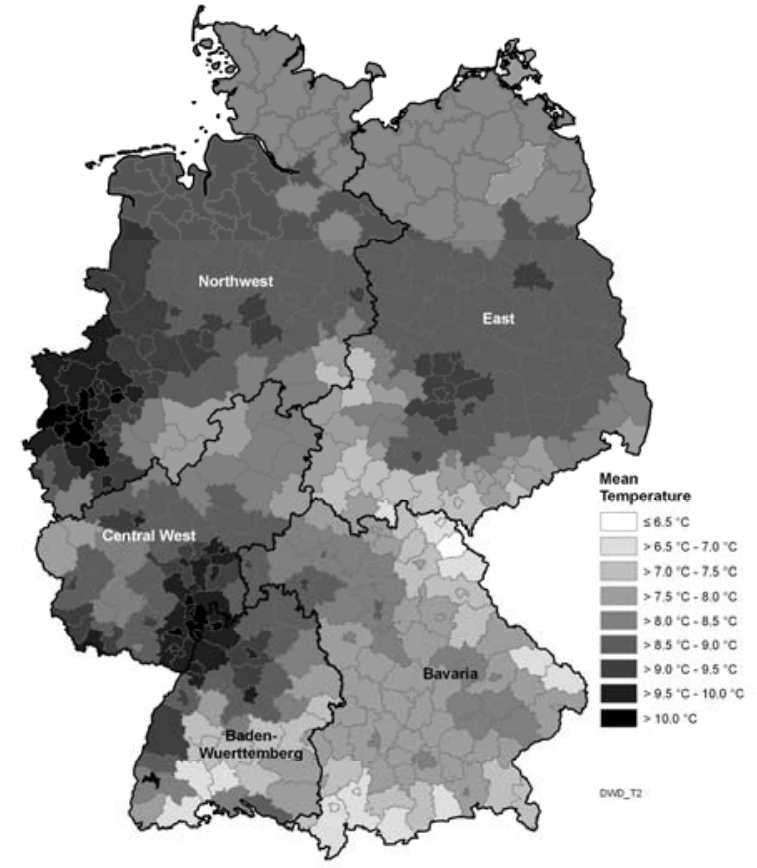

(a) Reference: Mean temperature (1961-1990).

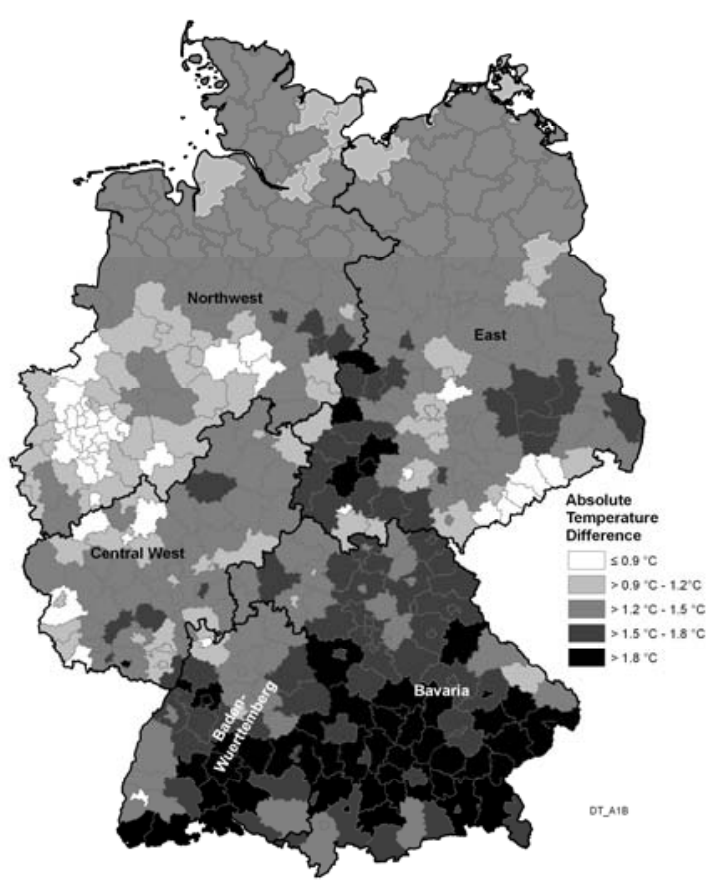

(b) Mean temperature changes (2011-2040) for scenario A1B.

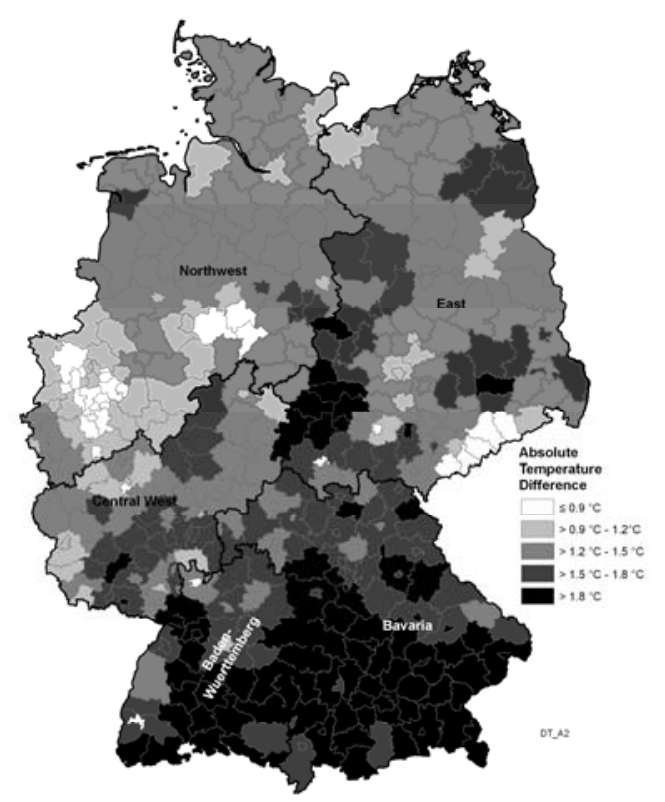

(c) Mean temperature changes (2011-2040) for scenario A2.

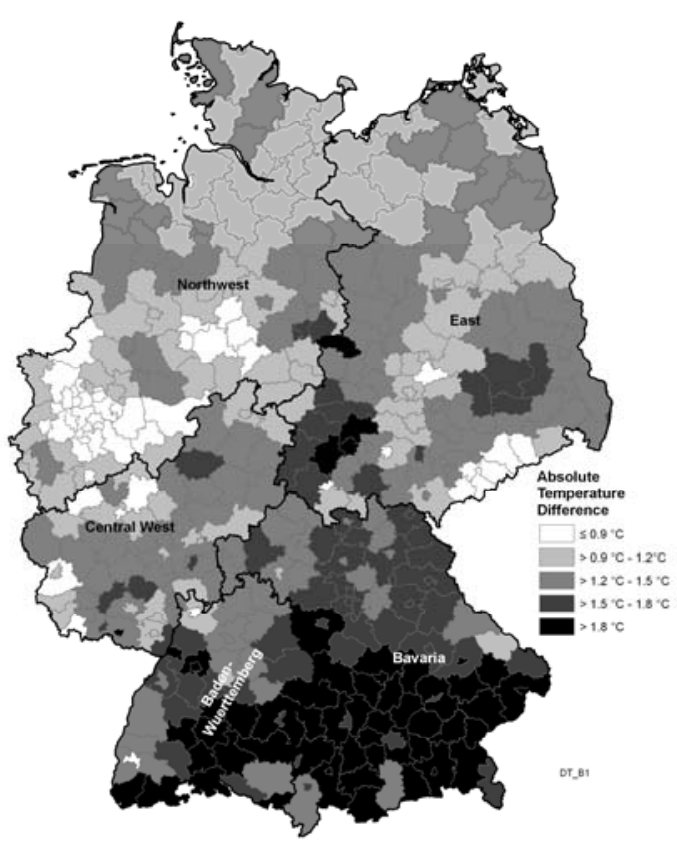

(d) Mean temperature changes (2011-2040) for scenario B1.

Source: our own estimations based on data by DWD 2007 and MPI on behalf of the Umweltbundesamt 2006.

Fig 1 Mean temperature 1961-1990 and predicted mean temperature changes 2011-2040 for three different climate scenarios 


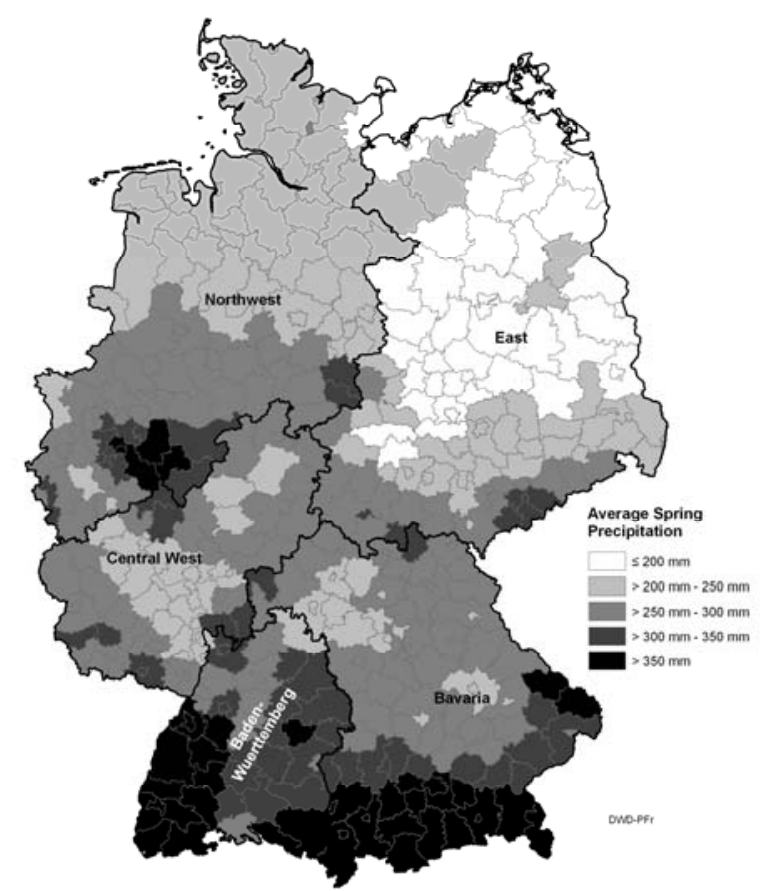

(a) Reference: Average spring precipitation (1961-1990).

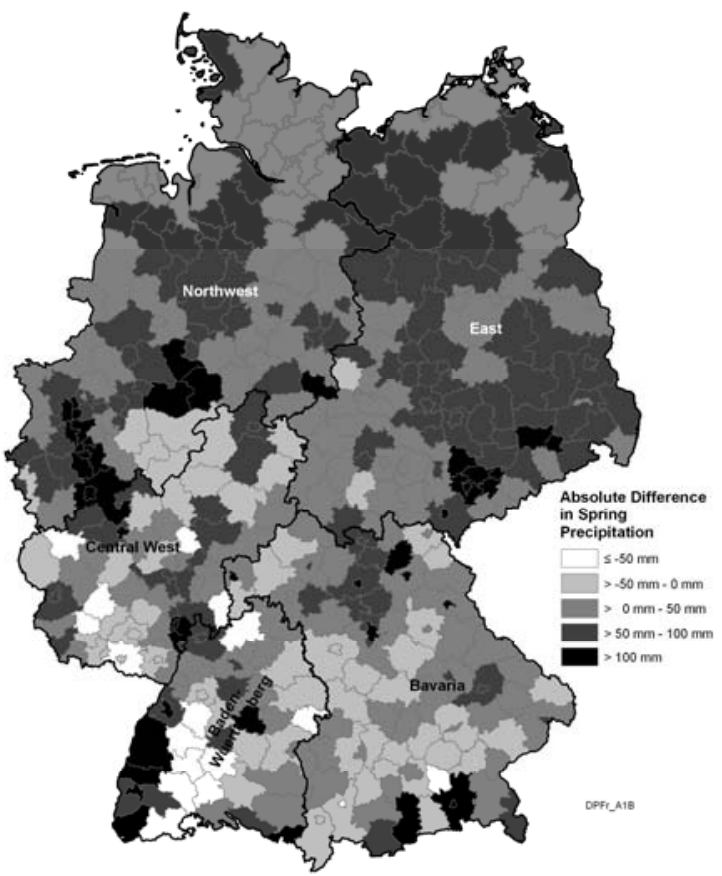

(b) Average spring precipitation changes (2011-2040) for scenario A1B.

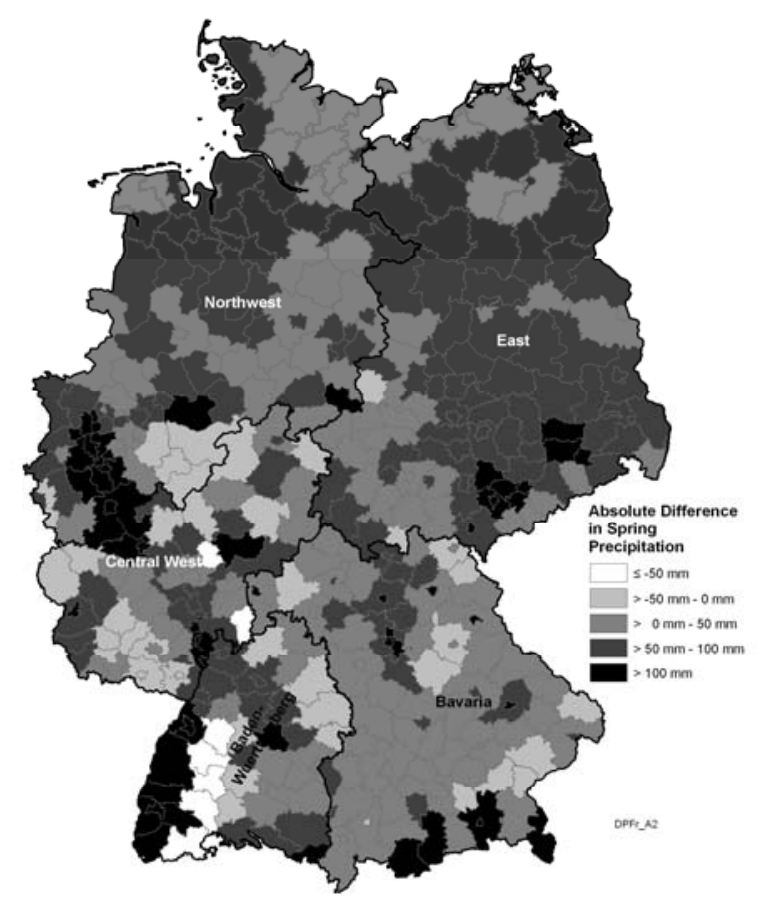

(c) Average spring precipitation changes (2011-2040) for scenario A2.

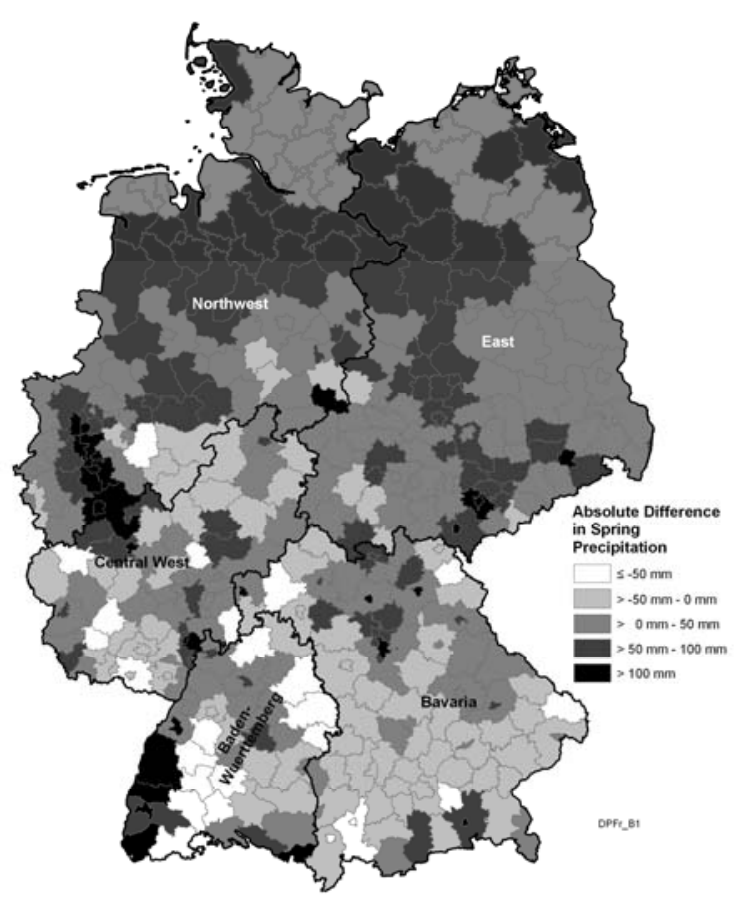

(d) Average spring precipitation changes (2011-2040) for scenario B1.

Source: our own estimations based on data by DWD 2007 and MPI on behalf of the Umweltbundesamt 2006.

Fig 2 Average spring precipitation from April to June 1961-1990 and predicted average spring precipitation changes 2011-2040 for three different climate scenarios 


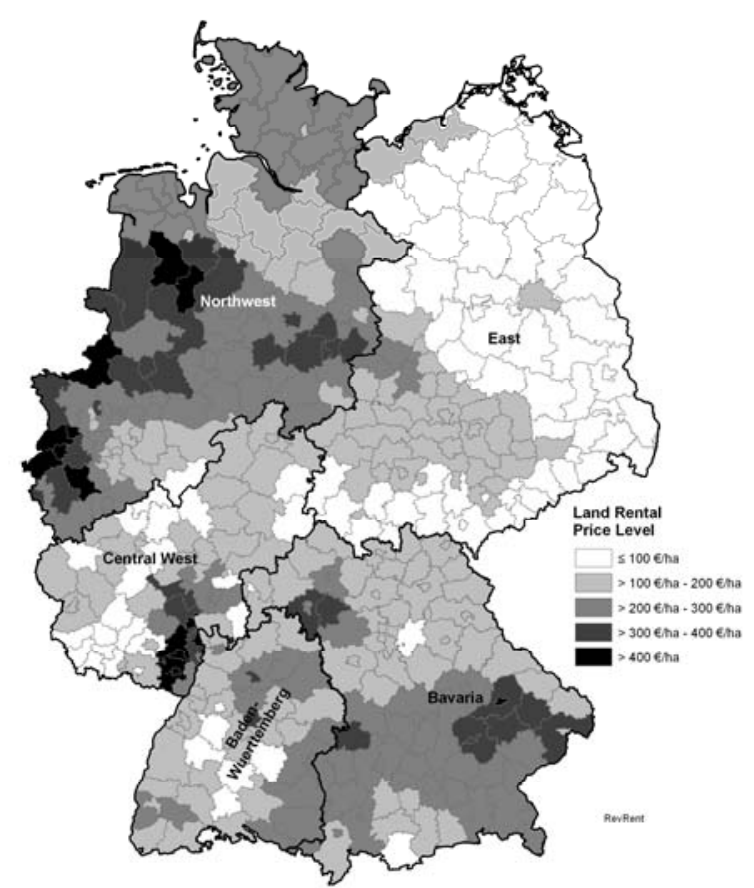

(a) Reference: Average land rents (1961-1990).

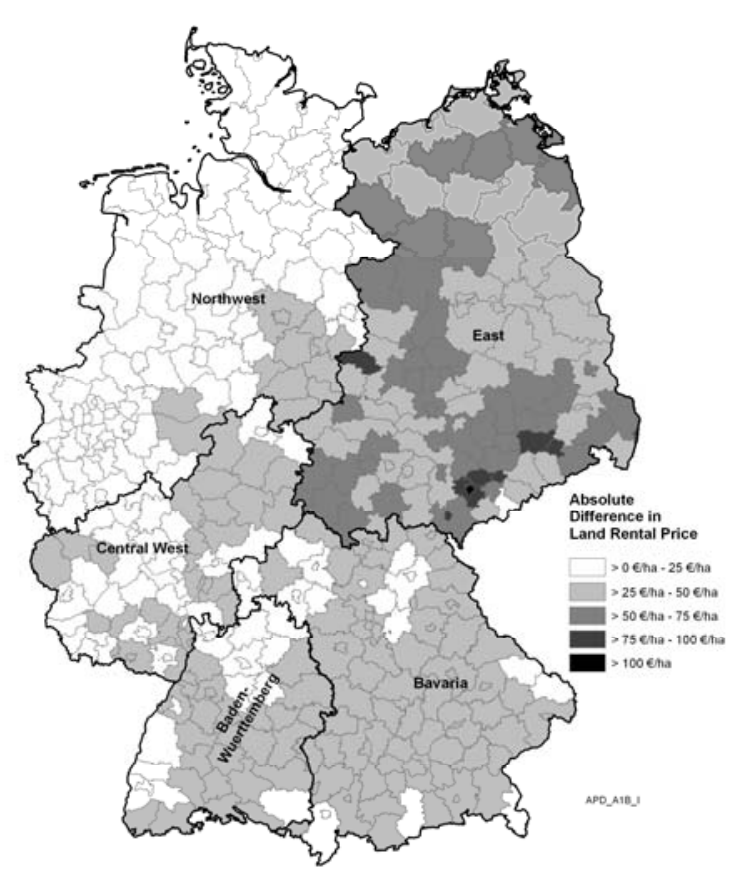

(b) Average land rent changes (2011-2040) for scenario A1B (Model I).

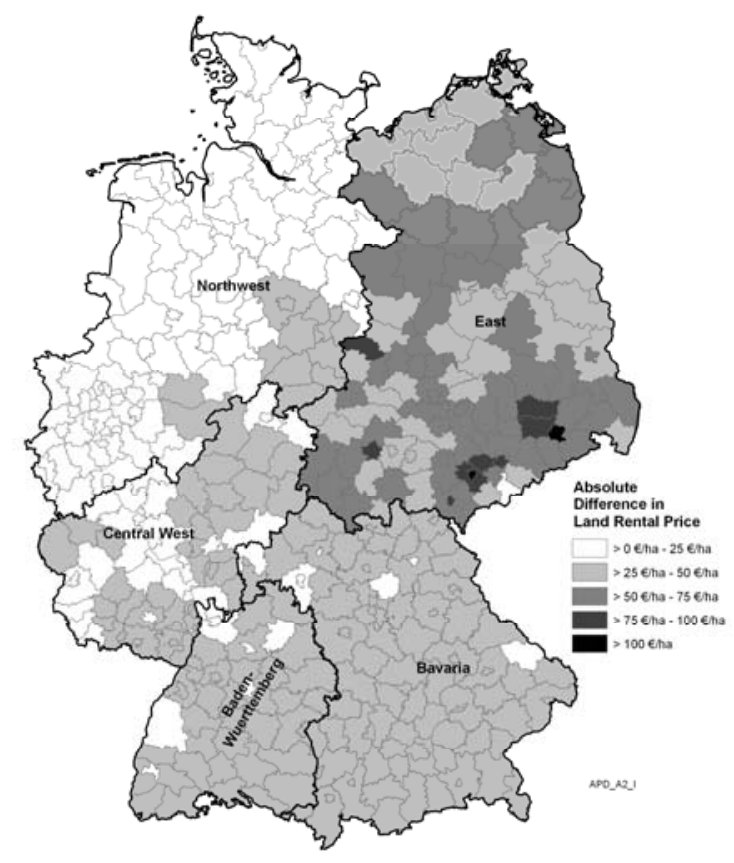

(c) Average land rent changes (2011-2040) for scenario A2 (Model I).

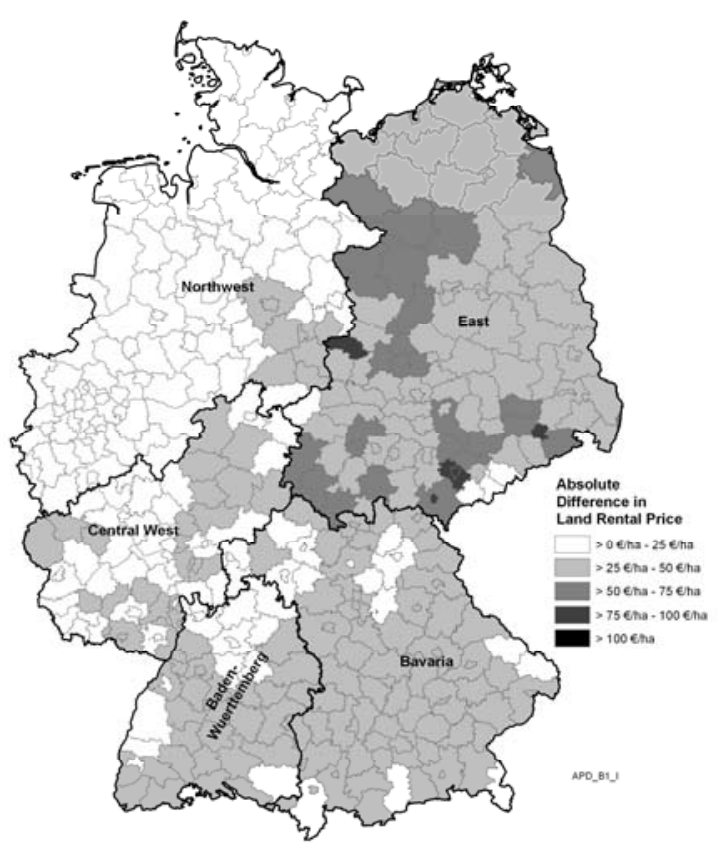

(d) Average land rent changes (2011-2040) for scenario B1 (Model I).

Source: our own estimations based on data by Statistisches Landesamt Baden-Wuerttemberg 2007; Statistische Ämter des Bundes und der Länder 2001; DWD 2007 and MPI on behalf of the Umweltbundesamt 2006.

Fig 3 Average land rent in 1999 and predicted land rent changes (Model I) for three different climate scenarios (mean temperature and spring precipitation averages for 2011 through 2040) by district 


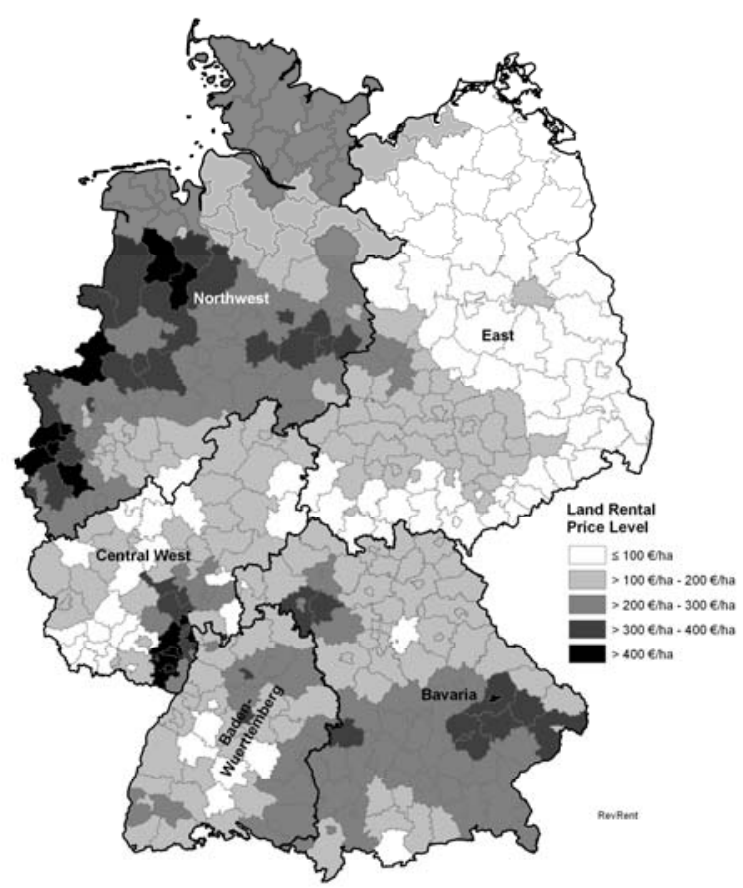

(a) Reference: Average land rents (1961-1990).

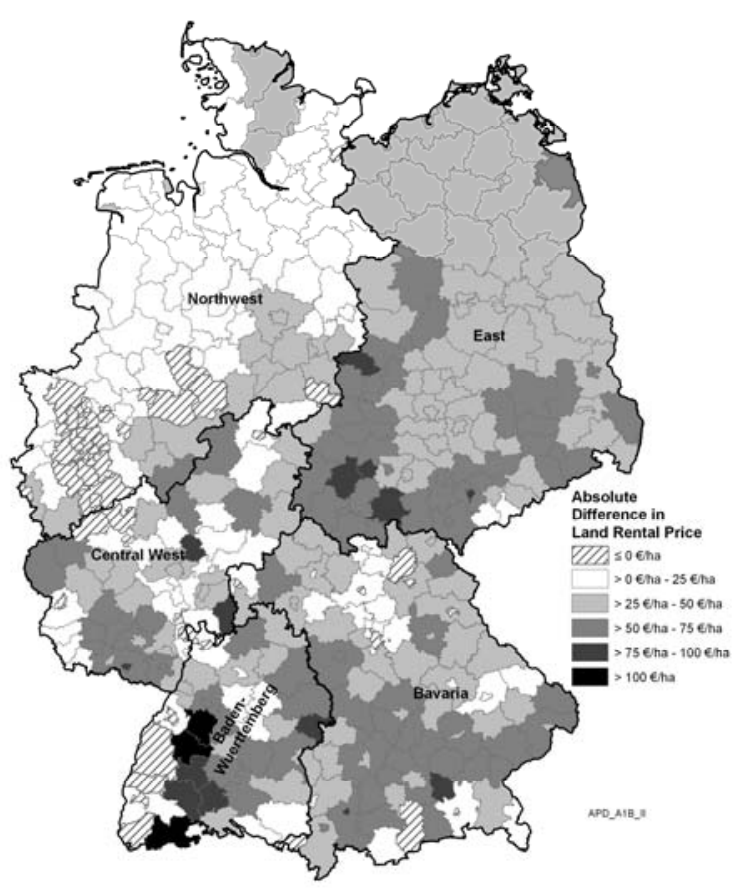

(b) Average land rent changes (2011-2040) for scenario A1B (Model II).

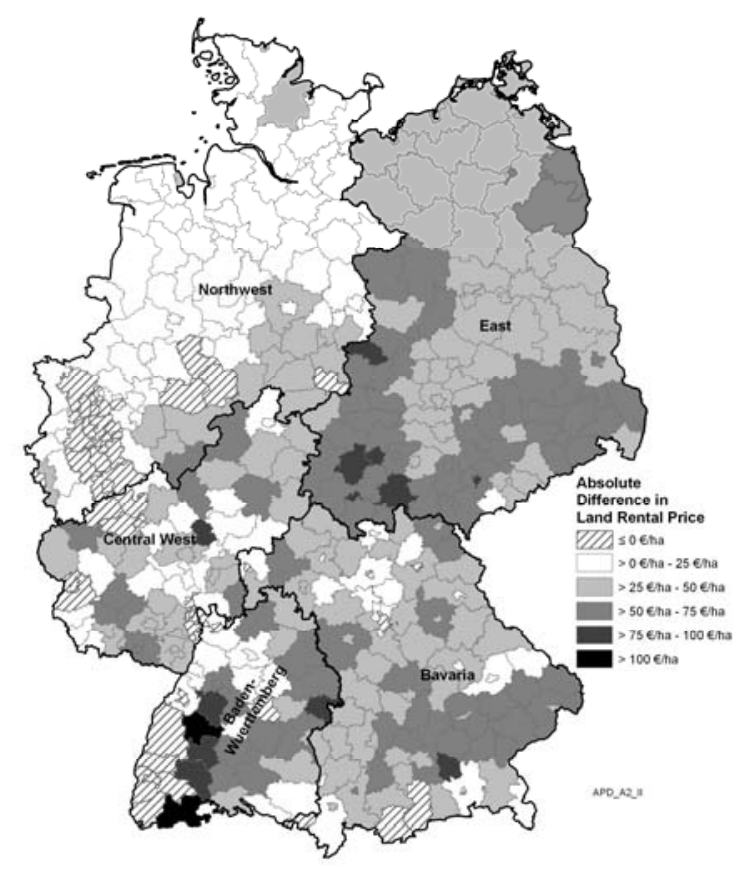

(c) Average land rent changes (2011-2040) for scenario A2 (Model II).

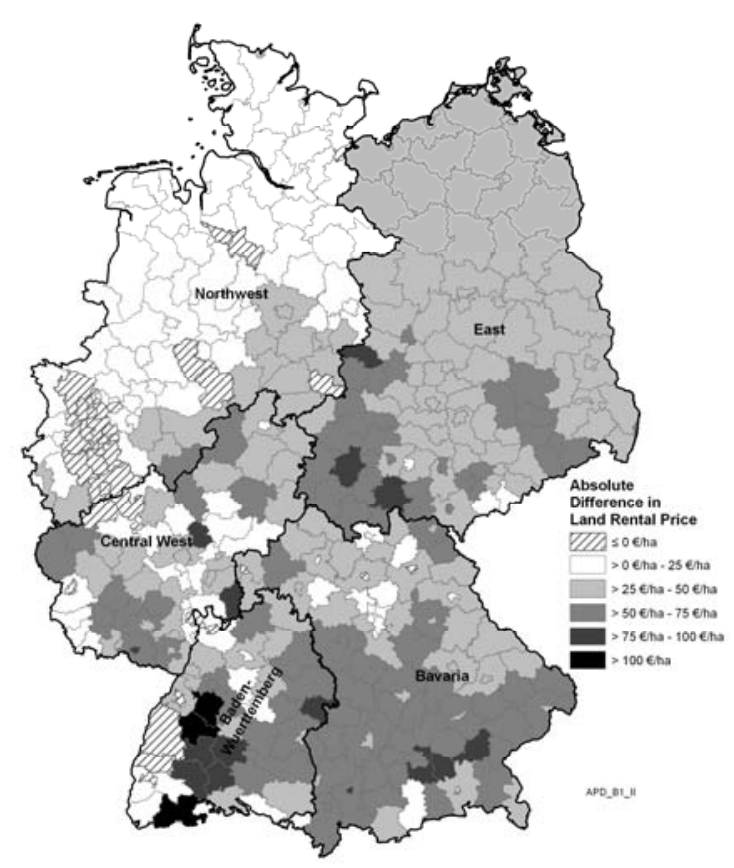

(d) Average land rent changes (2011-2040) for scenario B1 (Model II).

Source: our own estimations based on data by Statistisches Landesamt Baden-Wuerttemberg 2007; Statistische Ämter des Bundes und der Länder 2001; DWD 2007 and MPI on behalf of the Umweltbundesamt 2006.

Fig 4 Average land rent in 1999 and predicted land rent changes (Model II) for three different climate scenarios (mean temperature and spring precipitation averages for 2011 through 2040) by district 


\section{Discussion}

Thus far, only a few Ricardian studies of European climate change exist (Lang 2007: 424). The problem is that most European countries are small, and no consistent administrative structure throughout the European Union exists that would facilitate a Europe-wide analysis. Unfortunately, the European statistical classification system NUTS (Nomenclature of territorial units for statistics, cf. EC 2003) cannot remedy this problem. This common regional classification system was developed to have comparable statistical data for all member states. However, the necessary data for an analysis covering all member states was not available at NUTS 3 level (corresponding to the German districts), which was chosen for this study. Thus, it is quite difficult to obtain a significant statistical model for capturing the effects of changing climatic conditions, since the climatic settings of the districts underlying the cross-sectional analysis are rather similar within countries like the Netherlands. For Germany, which is one of the bigger EU countries, significant results could be produced. However, these results presented above are subject to some reservations.

In all, there is evidence that important factors influencing land rent were not among the explanatory variables available for our study. In particular, there was no variable reflecting a district's average soil quality: the soil-climate index (BKZ) provided by the Federal Office for Building and Regional Planning is a relative measure incorporating both soil and climate characteristics, and thus it is impossible to separate out soil quality. However, by using a spatial error model, we tried to get an efficient estimate of the marginal climate effects. In this context, it should be noted that the district level is still a relatively large spatial scale, but data could not be obtained for lower spatial scales.

One caveat is the possible existence of omitted variables correlated with one of the explaining variables contained in our models. This is particularly relevant for variables that cannot be controlled by farmers when adapting to climate change. In this context, the farmland's slope, which we did not know for the different districts, could lead to an overestimation of climate change related profits: if slope was negatively correlated with average temperature (in case average slope was significantly greater in colder mountain regions) as well as with land rents, the coefficient for average temperature will feature an exaggerated positive effect on the land rental price (implying that farmers could change the slope of their fields when temperature rises). In contrast, correlation of average temperature with a presumably endogenous omitted variable like livestock density (e.g. due to temperature dependent profitability of fodder production) is not that problematical because in this case the adjustment of livestock is part of farmers' adaptation to a long-term change in temperature.

The expected inversely u-shaped relationships between temperature or precipitation on the one hand and the land rental price on the other could not be established with the analysed data. At present, most parts of Germany have plenty of water. However, water scarcity may become a problem in the future, and then the negative relationship between precipitation and land profitability found above will no longer hold. There is already a positive relationship for East Germany (see the corresponding coefficients in model II, Table 1), which has an important share of relatively dry regions. It should be noticed that our equations were virtually estimated for rain fed farmland, since at present irrigation is of little importance in German agriculture. Nevertheless, in the long run, in increasingly dry districts irrigation might be used to mitigate climate change damages. But then, according to Schlenker et al. (2005) like in the United States different regression equations should be estimated for 'dryland' and irrigated areas in order to obtain unbiased regression coefficients. In this context, it should also be noticed that for California, a relatively dry country, Schlenker et al. (2007) found a significant influence of surface water availability on land values. 
Also, an increase in weather variability and extreme events like heat waves could affect land rents. At present, there is merely partial evidence for such an increase (Zebisch et al. 2005: 38f.), but when it occurred, it would ultimately entail higher insurance costs for the farming sector.

As in every Ricardian analysis, adjustment and transaction costs linked to the assumed farmers' adaptation were not accounted for, since this method implies the comparison of two different economic equilibria without consideration of the dynamic processes that lead from the present equilibrium to the future one. The related costs will diminish the farmers' profits. In contrast, our analysis assumed the relative prices that brought about the 1999 land rents would remain approximately the same at the 2025 time horizon (unless the predicted land rent changes were biased). In any event, in addition to the profits presented in Table 2, German farmers may benefit from the decrease in worldwide cereal production currently expected to be induced by climate change and the corresponding higher world price level (von Braun 2007: 3f.).

Furthermore, a possible fertilisation effect linked to a rising $\mathrm{CO}_{2}$ content in the atmosphere may entail an additional benefit not contained in the estimations above, since the higher future $\mathrm{CO}_{2}$-contents could not have been observed in the past. In general, rent estimations are problematic in cases where the predicted climate is quite different when compared with the reference situation. Strong extrapolation should be avoided. Thus, the projected temperature and precipitation changes should not exceed the ranges of the data underlying the parameter estimates. Because of new farming methods and plant breeds which may be developed over time, a Ricardian climate-change impact assessment for very long time horizons does not make sense. Hence, what will happen to German agriculture in the case of the stronger temperature increases predicted by the end of this century cannot be figured out by means of Ricardian analyses.

Assuming business-as-usual, Zebisch et al. (2005) show agriculture in East and Southwest Germany to be highly vulnerable to climate change. In East Germany, the climatic water balance, already unfavourable, will be further deteriorated by the expected decrease in summer precipitation and increased evaporation brought about by rising temperatures. In the Southwest, the region with the highest temperatures in Germany at present, the expected rapid warming will cause problems. Scenario calculations with the regional climate model REMO until the end of this century show the highest temperature increase in South and Southeast Germany and the strongest decrease in summer precipitation in South, Southwest and Northeast Germany (UBA 2006). Also, scenario simulations with the statistical, regional climate model WETTREG show a strong decrease in summer precipitation in Northeast Germany (Spekat et al. 2007), where the relationship between spring precipitation and land rental price is positive. Moreover, as we cannot be sure that the regression coefficients found will also be valid when extrapolating for more serious climate changes, for higher average temperatures (higher than those observed at present in the warmest German districts) its correlation with land rental prices could be negative.

Hence, by the end of this century, when temperature and precipitation changes will be more important than those simulated in this paper, German agriculture might experience losses, even though in the medium term, as our results show, it will benefit from climate change. 


\section{References}

Anselin L (1988) Spatial Econometrics: Methods and Models. Kluwer, Dordrecht

BMVEL (Bundesministerium für Verbraucherschutz, Ernährung und Landwirtschaft) 2001 Agrarbericht der Bundesregierung 2001. Bonn, Germany

BMVEL (Bundesministerium für Verbraucherschutz, Ernährung und Landwirtschaft) (2004) Ernährungs- und agrarpolitischer Bericht der Bundesregierung 2004. Berlin, Germany

Deschênes O, Greenstone M (2007) The Economic Impacts of Climate Change: Evidence from Agricultural Output and Random Fluctuations in Weather. Am Econ Rev 97(1):354385

DWD (Deutscher Wetterdienst) (2007) Mittelwerte aller DWD Stationen der Periode 19611990, www.dwd.de/de/FundE/Klima/KLIS/daten/online/nat/index_mittelwerte.htm. Accessed 31 July 2007

EC (2003) Regulation (EC) No 1059/2003 of the European Parliament and of the Council of 26 May 2003 on the establishment of a common classification of territorial units for statistics (NUTS). Official Journal of the European Union, L 154/1, 21 ${ }^{\text {st }}$ June 2003

Gerstengarbe F-W, Werner PC, Österle, H, Wodinski M (2005) Klimatische Belastungen und Extreme. In: Stock M (ed), KLARA, Klimawandel - Auswirkungen, Risiken, Anpassung. PIK Report 99, pp 21-45

IPCC (Intergovernmental Panel on Climate Change) (2007a) Fourth assessment report Climate Change. WG I and WG II, Geneva, www.ipcc.ch. Accessed 10 Dec 2007

IPCC (Intergovernmental Panel on Climate Change) (2007b) Summary for Policymakers. In: Solomon S, Qin D, Manning M, Chen Z, Marquis M, Averyt KB, Tignor M, Miller HL (eds) Climate Change 2007: The Physical Science Basis. Contribution of Working Group I to the Fourth Assessment Report of the Intergovernmental Panel of Climate Change. Cambridge University Press, Cambridge

Jacob D (2001) A note to the simulation of the annual and inter-annual variability of the water budget over the Baltic Sea drainage basin. Meteorol Atmos Phys 77:61-73

Jacob D, Podzun, R. (1997) Sensitivity studies with the regional climate model REMO. Meteorol Atmos Phys 63:119-129

Kolstad CD (2000) Environmental Economics. Oxford University Press, New York

Lang, G (2007) Where are Germany's gains from Kyoto? Estimating the effects of global warming on agriculture. Clim Change 84:423-439

LeSage J (1999) Spatial Econometrics. Department of Economics, University of Toledo (USA), www.rri.wvu.edu/WebBook/LeSage/spatial/spatial.html. Accessed 4 Feb 2003

LeSage J (2003) Econometrics Toolbox. www.spatial-econometrics.com, Accessed Feb 2003

Mendelsohn R (2007) Measuring Climate Impacts with Cross-Sectional Analysis. Introduction to the Special Issue in Climatic Change. Clim Change 81:1-7

Mendelsohn R, Reinsborough, M (2007) A Ricardian Analysis of US and Canadian Farmland. Clim Change 81:9-17

Mendelsohn R, Nordhaus WD, Shaw D (1994) The Impact of Global Warming on Agriculture: A Ricardian Analysis. Am Econ Rev 84(4):753-771 
MPI on behalf of the Umweltbundesamt (2006) REMO-UBA scenario data. CERA-database (Climate and Environmental Data Retrieval and Archive), WDCC (World Data Center for Climate). Modelle \& Daten. http://cera-www.dkrz.de. Accessed 27 Nov 2007

Patton M, McErlean S (2003) Spatial Effects within the Agricultural Land Market in Northern Ireland. J of Agric Econ 54(1):35-54

Polsky C, Easterling WE III (2001) Adaptation to climate variability and change in the US Great Plains: A multi-scale analysis of Ricardian climate sensitivities. Agric Ecosyst Environ 85:133-144

Schlenker W, Roberts M (2006) Nonlinear Effects of Weather on Corn Yields. Rev Agric Econ 28(3):391-398

Schlenker W, Hanemann, WM, Fisher AC (2005) Will U.S. Agriculture Really Benefit from Global Warming? Accounting for Irrigation in the Hedonic Approach. Am Econ Rev 95(1):395-406

Schlenker W, Hanemann, WM, Fisher AC (2006) The Impact of Global Warming on U.S. Agriculture: An Econometric Analysis of Optimal Growing Conditions. Rev Econ Stat 88(1):113-125

Schlenker W, Hanemann, WM, Fisher AC (2007) Water Availability, Degree Days, and the Potential Impact of Climate Change on Irrigated Agriculture in California. Clim Change 81:19-38

Schulzweida U, Kornblueh L, Quast R (2007) CDO User's Guide. www.mpimet.mpg.de/fileadmin/software/cdo. Accessed 27 Nov 2007

Spekat A, Enke W, Kreienkamp F (2007) Neuentwicklung von regional hoch aufgelösten Wetterlagen für Deutschland und Bereitstellung regionaler Klimaszenarios auf der Basis von globalen Klimasimulationen mit ECHAM5/MPI-OM T63L31 2010 bis 2100 für die SRES-Szenarios B1, A1B und A2. Endbericht im Rahmen des Forschungs- und Entwicklungsvorhabens: „Klimaauswirkungen und Anpassungen in Deutschland - Phase I: Erstellung regionaler Klimaszenarios für Deutschland“ des Umweltbundesamtes. www.umweltbundesamt.de. Accessed Jan 2007

Statistische Ämter des Bundes und der Länder (2001) Statistik regional. Daten und Informationen. CD ROM

Statistisches Landesamt Baden-Württemberg (2007) Communication of the 1999 land rental prices in German districts, collected by the statistical offices of Germany. Stuttgart, August 2007

UBA (Umweltbundesamt) (2006) Künftige Klimaänderungen in Deutschland - Regionale Projektionen für das 21. Jahrhundert. Hintergrundpapier, April 2006, updated in September 2006. www.umweltbundesamt.de

von Braun J (2007) The World Food Situation: New Driving Forces and Required Actions. IFPRI's Biannual Overview of the World Food Situation presented to the CGIAR Annual General Meeting, Beijing, December 4, 2007. International Food Policy Research Institute (IFPRI), Washington

Zebisch M, Grothman T, Schröter D, Hasse C, Fritsch U, Cramer W (2005) Climate Change in Germany, Vulnerability and adaptation of climate sensitive sectors. Environmental research of the federal ministry of the environment, nature conservation and nuclear safety, research report 20141 253, UBA-FB 000844/e. www.umweltbundesamt.de 